
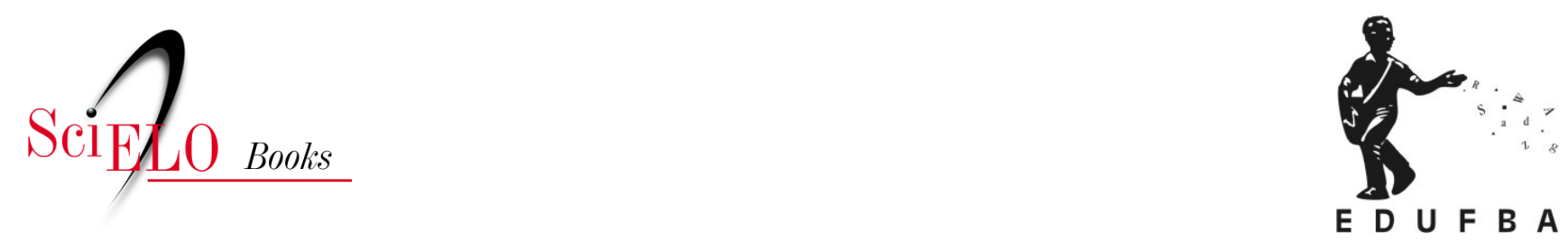

\title{
As viúvas do amianto significados da contaminação por asbesto
}

\author{
Cláudia de Oliveira d'Arede \\ Mônica Angelim Gomes de Lima \\ Maria do Carmo S. Freitas
}

\section{SciELO Books / SciELO Livros / SciELO Libros}

D'AREDE, C.O., LIMA, M.A.G., and FREITAS, M.C. As viúvas do amianto: significados da contaminação por asbesto. In: FERNANDES, R.C.P., LIMA, M.A.G., and ARAÚJO, T.M., comps. Tópicos em saúde, ambiente e trabalho: um olhar ampliado [online]. Salvador: EDUFBA, 2014, pp. 333-357. ISBN: 97865-5630-012-2. https://doi.org/10.7476/9786556300122.0017. \section{International license.}

All the contents of this work, except where otherwise noted, is licensed under a Creative Commons Attribution 4.0

Todo o conteúdo deste trabalho, exceto quando houver ressalva, é publicado sob a licença Creative Commons Atribição 4.0. 


\section{As viúvas do amianto: significados da contaminação por asbesto}

Cláudia de Oliveira d'Arede Mônica Angelim Gomes de Lima Maria do Carmo S. Freitas

\section{Introdução}

Este capítulo apresenta um estudo etnográfico sobre os significados da contaminação por amianto da mina de São Felix, em Bom Jesus da Serra, Bahia. O estudo objetiva compreender os significados desta contaminação, a partir do discurso das viúvas de trabalhadores desta mina, que em sua percepção, faleceram em decorrência das doenças provocadas pelo amianto. Este estudo analisa o discurso das viúvas e recupera o significado da contaminação para esta comunidade.

Inicialmente serão apresentadas algumas considerações sobre o uso do amianto e o contexto de sua produção no local de estudo (a comunidade que vive nas proximidades da mina de São Félix). Em seguida serão analisadas as percepções das mulheres sobre o processo de contaminação, doença e morte de seus companheiros. Por fim, serão discutidos aspectos do contexto atual e possibilidades de enfrentamento do problema.

\section{Breves considerações sobre o uso do amianto}

A relação do homem com o uso do asbesto (amianto) é antiga. Era considerado como aliado e facilitador na vida cotidiana, por ser um minério isolante térmico e resistente a altas temperaturas. Em diversas sociedades, os trabalhadores passaram a se expor cada vez mais ao pó do amianto utilizado em indústrias, como matéria prima para vários 
produtos, bem como ficaram expostos às fibras desse minério, em minas. No final do século XIX, alguns médicos observaram doenças em trabalhadores relacionadas ao amianto. (ABREA, 2001)

Figura 1 - Amianto in natura, encontrado na Mina de São Félix.

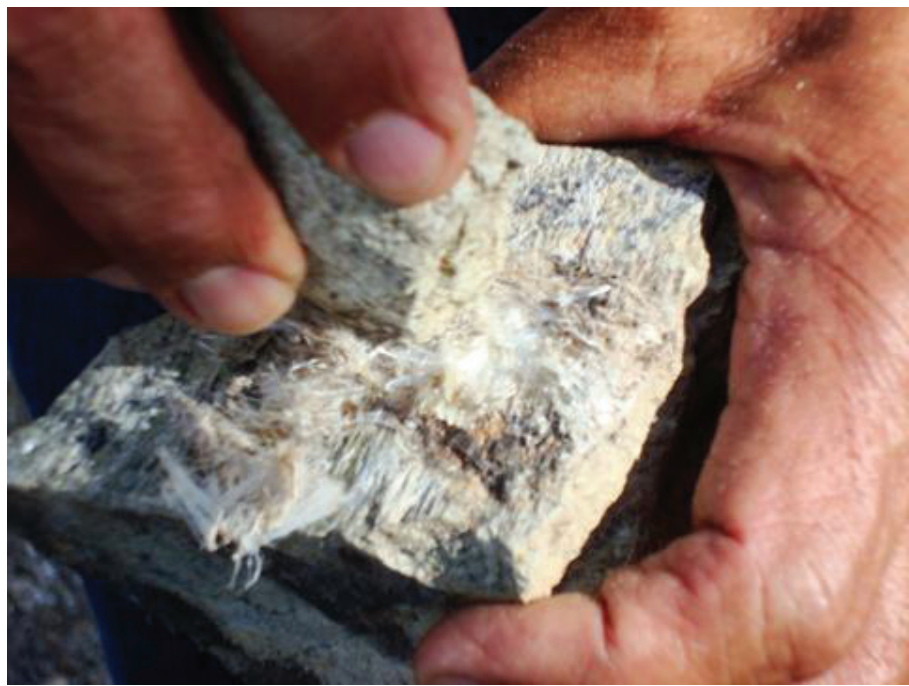

Fonte: (D'AREDE, 2008)

No momento, o amianto ou asbesto é responsável por aproximadamente 100.000 mortes por ano no mundo, segundo estimativa da OIT, principalmente por câncer de pulmão e mesotelioma de pleura. (BRASIL, 2008) O uso de todas as formas de fibras de amianto é proibido em 66 países, incluindo os da América do Norte e da Europa. No Brasil, o amianto do tipo anfibólio está banido desde 1991 pelo Ministério do Trabalho e Emprego em seu Anexo 12 da NR-15, que regulamentou e Convenção 162 da OIT, sendo depois ratificado com a Lei $\mathrm{n}^{\circ} 9055 / 95$, onde se proibiu definitivamente o uso do anfibólio. O Brasil mantém o uso da fibra crisotila, que é o tipo de amianto mais valorizado pela indústria. A Rússia e Cazaquistão lideram o ranking de produtores, seguidos de China, Canadá e Brasil. (REDE BANIMETRO INTERNACIONAL, 2006 apud IBAS, s.d) O Canadá é o segundo maior produtor mundial de amianto, porém consome pouco em seu território. Dados indicam que a população americana se expõe em média per capita a $100 \mathrm{~g} / \mathrm{ano}$; os canadenses a $500 \mathrm{~g} / \mathrm{ano}$; e a população brasileira a, aproximadamente, $1.400 \mathrm{~g} /$ ano. (CASTLEMAN, 1995) 
Até a década de 1930, o Brasil importava todo o amianto que consumia principalmente do Canadá e África do Sul. Em 1939, com a fundação da Sociedade Anônima de Mineração de Amianto - SAMA, este quadro começou a mudar com a descoberta da mina de São Félix em Bom Jesus da Serra, distrito do município de Poções, Bahia, marcando assim, o início de exploração no Brasil. Esta mina permaneceu ativa até 1967 e possuía aproximadamente 540 trabalhadores.

Em 1962, uma expedição geológica chegou a uma região de Goiás onde havia um modesto comerciante que vendia "estranhas pedras cabeludas". Assim foi descoberta a jazida que deu ao Brasil a autossuficiência no setor. Com a descoberta da imensa jazida em Goiás, no maciço de Canabrava, as instalações da mina de São Félix foram transferidas para essa região. Hoje, a Mina de Canabrava - única amiantífera em operação no país - produz amianto do tipo crisotila. Com ela, o Brasil ocupa a posição de terceiro maior produtor mundial, suprindo todo o consumo interno e exportando para dezenas de países. Sua produção atinge aproximadamente 180.000 toneladas/ano. (PAMPLONA, 2003) A cadeia produtiva do amianto crisotila brasileiro, desde a mineração até a revenda dos produtos derivados, gera 170 mil empregos no país. De toda a produção de crisotila brasileira, $6 \%$ é usada em produtos de fricção, massas de vedação, entre outros e $94 \%$ em produtos de cimento amianto: $50 \%$ dos telhados e $80 \%$ das caixas de água brasileiras são fabricados com cimento amianto. (ABREA, 2001)

A grande cava aberta entre as pedras de amianto na mina de São Félix tem um quilômetro de extensão e cerca de setenta metros de profundidade, assim como seus túneis não estão resguardados da presença de pessoas e animais. "O grande cânion”, como é chamado pelos moradores, o lago de águas verdes, possui concentração de magnésio na sua composição, a partir de rochas amiantíferas, dando origem à cor da água esverdeada, e levemente salgada, onde ainda se pesca tilápias, traíras e tambaquis, ainda que seu consumo ofereça perigo à saúde. 
Figura 2 - Mina de São Félix, desativada.

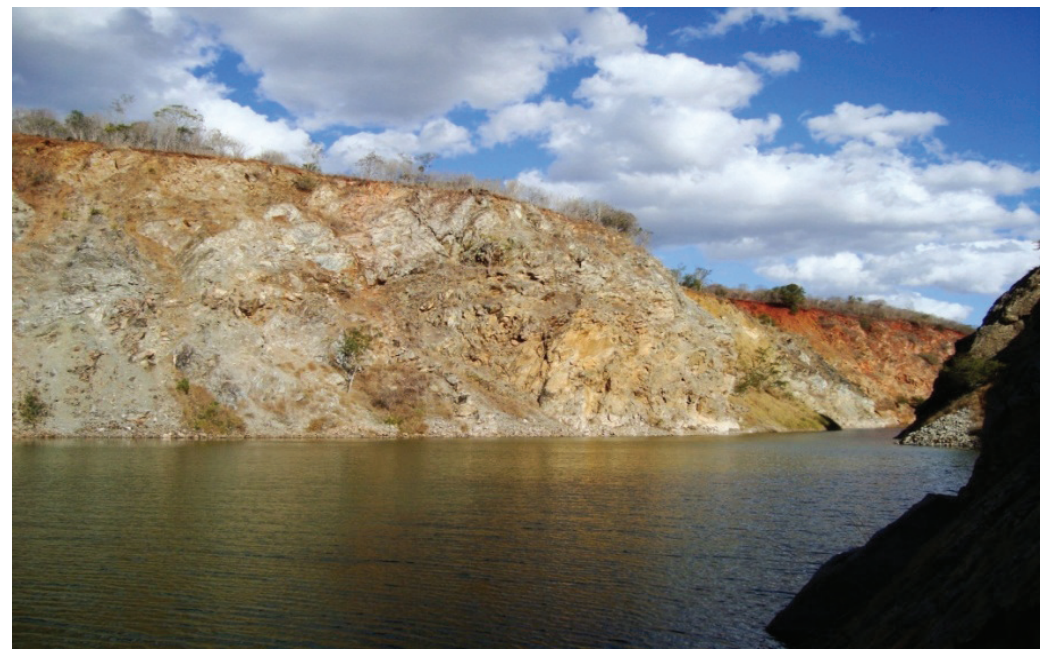

Fonte: (D'AREDE, 2008)

Ainda são desconhecidas as significações deste mineral por pessoas que vivem na região, mesmo tendo a presença do amianto em várias ruas pavimentadas e casas construídas. Hoje, a mina abandonada é local de lazer, de banhos de sol e pesca pela comunidade. Conhecer o processo de adoecer e viver, no cotidiano com o amianto, estruturou alguns dos movimentos deste estudo etnográfico sobre a percepção da contaminação por esse minério. Estas informações denunciam a falta de ações sociais para a melhoria das condições de vida e saúde dos moradores.

\section{As viúvas do amianto: abandono e sobrevivência}

Os discursos das viúvas, aqui analisados, apresentam as lembranças de seus maridos, seu trabalho, o envelhecimento e o abandono que sentem pela falta de apoio da Empresa mineradora e do Estado. Estas questões se configuram como marcas significantes de mudanças, nas identidades dessas mulheres idosas e sozinhas.

Para elas, a "poeira" ou "pó do minério" representa um perigo para a saúde, uma contaminante que provoca vários sintomas e doenças. Entre 
as mais graves estão: o câncer de pulmão, de pleura (mesotelioma) e a asbestose pulmonar - pneumopatia crônica obstrutiva. (BRASIL, 2008)

A análise das redes semânticas das narrativas dessas mulheres apresenta como significantes principais a descrição das enfermidades de seus maridos, marcadas por várias perspectivas. Sobre isto, Byron Good (1994), mostra que a noção de rede semântica indica que o significado de uma doença não é unívoco, mas, um produto plural e interconectado a vários sentidos. Trata-se de relacionar experiências, palavras, sentimentos e ações dos diferentes membros da sociedade. Nesse aspecto, esta investigação antropológica sobre os significados da contaminação por asbesto, interpreta aspectos da realidade e da experiência dos trabalhadores e de suas famílias com o amianto, significados e noções sobre o processo saúde/doença, riscos passados, presentes e futuros decorrentes da exposição do corpo ao amianto.

As histórias sobre o trabalho na mina, adoecimentos e mortes, são partes da memória preservada por viúvas e pelas lápides brancas do cemitério "Brancas de Neve", na Vila Operária. As viúvas denunciam, com indignação, a poeira branca que seus maridos "guardaram no corpo" até à morte. Este estudo como vemos a seguir, reúne informações para tornar visível este problema ambiental e de saúde dos trabalhadores. Nesse sentido, faz-se um intercâmbio de experiências através da narrativa partilhada, produzida no momento etnográfico que envolve o pesquisador e as narradoras, as viúvas do amianto. (BENJAMIM, 1987)

\section{Metodologia}

Trata-se de uma etnografia com análise dos significados atribuídos por viúvas de trabalhadores mineiros que faleceram ao longo da exploração da mina. Ademais das interpretações narrativas, foi realizada a observação participante com um rigoroso registro do modo de vida das famílias do povoado de São Félix. (OLIVEIRA, 2000)

Para Oliveira (2000, p.96-7)

[...] não há descrição, por mais intencionalmente objetiva que seja, sem um mínimo de interpretação [...]. Distingo interpretação de compreensão seguindo Paul Ricoeur quando esse autor examina a relação dialética entre compreensão e explicação em vários de seus escritos. 
Sobre este aspecto, este estudo utiliza teorias compreensivas e interpretativas. (GEERTZ, 1999; RICOEUR, 2009) Os registros obtidos em campo somam-se às descrições analíticas sobre a história do lugar, o abandono das famílias, pela Empresa mineradora e pelo Estado. Busca-se, com isso, a compreensão da contaminação ocupacional ocorrida há mais de quarenta anos e que levou à morte vários trabalhadores desta mina. São as suas viúvas que contam como era o trabalho, os sintomas de adoecimento, o meio ambiente resultante das atividades de exploração do amianto e o fechamento e abandono da mina. O trabalho de campo foi realizado no período de janeiro a dezembro de 2008, com registros diários sobre o cotidiano das famílias. (MINAYO, 1992; GEERTZ, 1999; OLIVEIRA, 2000)

Para sistematizar as informações obtidas das entrevistas em profundidade, foram aplicados três roteiros: o primeiro, baseado em Souza (2006), abordando a história de vida das viúvas, focalizando o trabalho de seus maridos na mina; o segundo, de acordo com Minayo (1992), sobre os modos de vida e saúde das viúvas e seus maridos; o terceiro, sobre a contaminação ambiental e ocupacional. Foram realizadas doze entrevistas com as viúvas e, dada à complexidade do processo interpretativo, foram feitas leituras e análises das informações com minuciosa e cuidadosa interpretação de cada entrevista, categorizando significantes em unidades de análises com os subconjuntos das falas. (BENJAMIM, 1980; RICOEUR, 1994)

Os critérios para escolha dos informantes-chave foram considerados indicações das lideranças da Associação Baiana de Expostos ao Amianto (ABEA), seguindo a recomendação desta pesquisa de apresentarem a descrição das histórias de doenças do asbesto e o tempo de trabalho ou de exposição dos trabalhadores na mina. Da observação e análise das narrativas que expressam a experiência das pessoas, buscou-se o caminho para a compreensão e interpretação dos significados atribuídos às viúvas (idade média 76 anos) ao processo de adoecimento e morte dos seus maridos, pelo amianto. 


\section{Resultados e discussão}

\section{Descrição do modo de vida da Vila Operária}

$\mathrm{Na}$ Vila Operária, durante o período em que a Empresa mineradora se manteve no local, as mulheres representavam dois tipos de papéis sociais: eram filhas de trabalhadores ou esposas. Algumas trabalharam na mina como ensacadoras de minério nas esteiras - o amianto era extraído à mão, com ajuda de um martelo, e depois vendido em sacos para a empresa. Ainda desenvolviam atividades domésticas de arrumadeiras na usina e na casa dos franceses (técnicos e donos da mineradora), lavadeiras e feirantes, além disso, cuidavam da sua própria casa e de sua família.

Os empregados da usina, que saíam do trabalho porque estavam doentes, eram obrigados a deixar as casas que pertenciam à Empresa mineradora, na Vila Operária. Assim, alguns trabalhavam doentes para não perderem o emprego, principal fonte de sustento das famílias, e para não serem despejados de suas casas. Desempregados, doentes e exaustos, migravam para outros lugares ou ficavam próximos à mina, em plantações de culturas de subsistência como feijão e milho, cuja venda era realizada na pequena feira da Vila Operária. Algumas mulheres trabalhavam na roça para complementar a renda, que nunca era suficiente.

Após o sofrimento e a morte do marido, a viúva era retirada da casa da Vila Operária. As viúvas do amianto eram acolhidas por outras famílias de trabalhadores do lugar, morando de favor entre os amigos e parentes.

Depois que o meu marido morreu, eu e meus filhos fomos todos pra fazenda do compadre Jovino, foram todos criados lá. Os meninos trabalharam na mina levando café, água para o povo do corte e vendia minério pra mineradora. (VIÚVA - JOSEFA, 2008)

O abandono das viúvas é expresso através da situação concreta de sofrimento e necessidades vividas a partir da sua condição de viuvez. Esse abandono pode ser percebido em relação à empresa, e aos agentes do Estado, enquanto responsável pelos registros de óbito e nascimento. Com a baixa escolaridade, elas não entendem e não conseguem tomar providências. 
As viúvas sobrevivem das pensões deixadas pelos maridos e como trabalhadoras rurais das atividades rurais de subsistência. As avós, viúvas ou não, permanecem com a guarda dos seus netos, especialmente em função de duas situações: pela morte prematura de seus filhos e pelo fluxo migratório para o centro-sul do país, especialmente para São Paulo, em busca de emprego. Assim, os filhos enviam, esporadicamente, economias para ajudar as mães. Mas, os laços são fortes. Os filhos que migraram ainda visitam suas mães quase todos os anos e algumas viajam para encontrá-los. Os que permanecem por perto, se casam, ficando junto das mães, geralmente morando no mesmo sítio, numa situação clara de matriarcado. A mãe, além de cuidar de netos, é a provedora da família, cuja subsistência é garantida pela agricultura familiar.

Os filhos das viúvas buscam trabalho "fora" da região. Muitos conseguem trabalhar como operários da construção civil e vendedores ambulantes. Nesse sentido, os filhos desempenham papel fundamental no sustento das famílias, repetindo a tradição do êxodo nordestino principalmente em direção à região sudeste do país: "Quando meu marido morreu, eu tinha dois rapazes. Eles foram pra São Paulo trabalhar. Depois eles escreveram dizendo que iam comprar um terreno pra mim e me deram o terreno". (VIÚVA - JOSEFA, 2008)

A condição de viúva remete a uma missão maior: na ausência definitiva do marido, o esforço humano para o sustento, é atribuído ao sagrado e aos filhos. A rede de apoio criada pela família é o suporte mais presente no estado de viuvez para estas mulheres. Estas e suas famílias atribuem significados ao lugar onde estão seus maridos. O cemitério tem uma representatividade de valor cultural: o culto aos túmulos. Estes são frequentemente visitados e ornamentados. As famílias, em especial as viúvas, procuram sentidos para continuarem perto dos seus maridos, realizando rezas junto aos túmulos. De certo modo, o cemitério é uma extensão da casa, pois entendem que seus maridos morreram precocemente. 
Figura 3 - Cemitério "Branca de Neve”, Bom Jesus da Serra, Bahia.

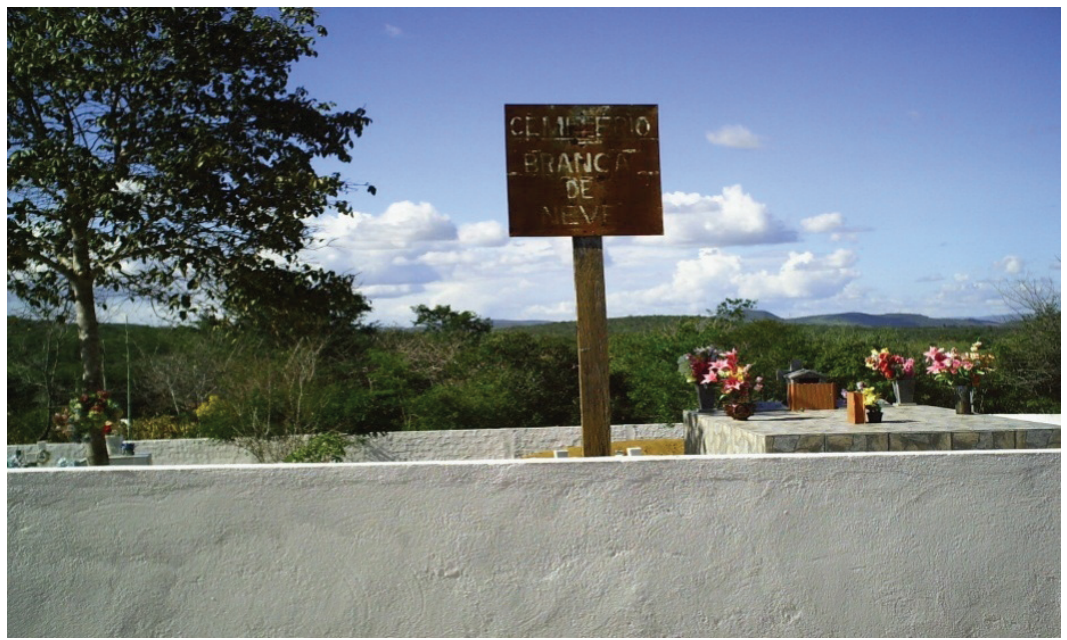

Fonte: (D'AREDE, 2008)

\section{O sentido da contaminação e do perigo}

Dizem que o minério faz mal, o povo fala que essa mina é um perigo. Eu não sei, mas eu acho que todos que vêm dessa região acusa que lá se trabalha até morrer. Tem uns que ficam resfriados, a tosse fica diferente. Meu pai ficou doente assim. (VIÚVA - JOSEFA, 2008)

"A usina, quando trabalhava, rodava os motores, aquela poeira saía tudo lá, fora a que ficava presa, que entrava no corpo. Saía voando, saía pro ar, era esparramado ali e lá embaixo enchendo saco, aquele pó [...]". (VIÚVA - STELA, 2008)

Para Mary Douglas (1991), as sociedades tradicionais concebem o meio físico como inseparável dos homens. Neste sentido, entendemos que para as viúvas do amianto a poeira deste minerio é parte da vida das pessoas do lugar. É compreendida como algo que entra no corpo e contamina. A contaminação é permanente por causa desse pó do amianto que ainda se encontra presente na mina, no campo de futebol, nas ruas, no ar, nos carros que passam e jogam poeira.

"Meu marido foi contaminado do minério, e morreu assim. Ele era moreno, chegava branquinho, caía poeira assim nos cabelos, olhos, na roupa". (VIÚVA - JOSEFA, 2008) 
"Sempre sentia, porque ele trabalhou na cama de poeira, não tem um que não ficou doente e outros, já morreram quase todo esse pessoal que trabalhava aí, muita gente morreu nova. Morreu todos desse pó". (VIÚVA - ISABEL, 2008)

A contaminação é compreendida de duas maneiras: durante a exposição à poeira na vida cotidiana da mina, e continua na mina abandonada. Trata-se de uma contaminação ocupacional e outra ambiental. A primeira ficou no passado e ainda ecoa no presente, a segunda permanece inalterada.

Com sete anos a doença começa. Nivaldo chegava do trabalho, tinha o macacão da cor dessa toalha (branca), ele não usava máscara. Os filhos dos trabalhadores não sabiam o que fazia mal, a gente almoçava lá, o restaurante lá dentro, trabalhava dentro do pó, mas a gente vivia lá, com todo mundo. (VIÚVA - OLÍVIA, 2008)

A desinformação sobre a contaminação é compreendida como "ofensa". O sentido é de adoecimento, o corpo "prejudicado". As mortes significam para as famílias, a consequência dessa ofensa. A Empresa mineradora e os agentes do Estado não protegeram estas pessoas.

\section{Atitudes sobre riscos e adoecimento}

Segundo Alves (2006), os estudos sobre a experiência da doença, tomam como ponto de partida analítico, o pressuposto de que o social é originalmente toda a situação vivida pelos atores sociais, em contextos culturais e históricos concretos. O mundo da vida ("Lebenswelt") é o horizonte de referência de valores, crenças e ideias, a partir do qual, os indivíduos e grupos sociais interagem entre si, definindo ações previstas de sentido e realizando qualquer empreendimento cognitivo como as "representações". Ao transportar este conceito para o escopo desse trabalho, observamos que as ações humanas em torno da mina, na relação entre contaminador e contaminado, traduzem-se em experiências fundadas no campo específico do mundo da vida, constituindo assim, a base sobre a qual se dão as demais relações sociais.

Ao partir da premissa de que a intersubjetividade se dá pela similitude de interpretações que ocorrem no mundo da vida cotidiana, é importante ressaltar, que para a fenomenologia hermenêutica, a 
doença é um fenômeno que diz respeito a um conjunto de elementos socioculturais que estão interligados entre si. (ALVES, 2006) O mundo da vida dessas viúvas está ilustrado em suas narrativas aqui analisadas. As viúvas desenvolveram processos de sofrimento que se assemelham entre elas, neste mesmo lugar. São diversos elementos comuns encontrados em suas narrativas, como se os fragmentos de suas etnobiografias revelassem a subjetivação da perda precoce dos maridos, como um castigo. (GONÇALVES; MARQUES; CARDOSO, 2012) Sentem a falta da correspondência, do afeto e do antigo lar. Em suas percepções, é como se houvesse "uma ferida aberta" em suas vidas de viúvas pelo amianto. Sobre a doença, descrevem: "Os pés dele eram assim aquele cascão, tudo que saía nas solas dos pés era minério”. (VIÚVA - JOSEFA, 2008) "Ele adoeceu. O umbigo dele era aberto, aqui (mostra o abdômen) inchou. É porque eu não tenho a placa pra te mostrar, mas podia botar a placa [pleural] em cima da barriga dele que dava assim". (VIÚVA - STELA, 2008)

A compreensão da contaminação e do adoecimento, se dá pela presença de placas do minério no corpo identificadas nos exames biomédicos. Apesar de não as reconhecer, sabem que o mal do minério (asbestose) está ali presentificado nas variações tonais de preto e branco do Raio X. No contexto deste estudo, saber sobre as placas no Raio X, ratifica o que é sentido no corpo ainda que a informação médica também tenha sido politicamente, valorizada pela Empresa para negar o diagnóstico ao paciente. E quanto à importância do diagnóstico para o paciente, Byron Good (1994), ao analisar a dor crônica e sua invisibilidade, pontua que ao ter um nome para a origem da dor (doença), tem-se também o poder de aliviar o sofrimento, um patamar crítico para a reconstrução do mundo cotidiano e uma autorização da integração do selfque sofre. (GOOD, 1994)

"Ele estava doente, mas não se deitava. Ele estava consciente de tudo. Conversava. E ele falava que tudo era do minério”. (VIÚVA BEATRIZ, 2008)

Eles (os médicos locais) não sabem identificar os problemas de asbestose. Disseram pra levar ele lá e ele passando mal. Depois viram as chapas que a gente tinha tirado, pegaram e saíram. Ainda tem duas chapas de raios-X, tudo pretinho. Não se vê nada de pulmão. Vieram uns advogados da firma. Aí eles engabelaram a gente, falou que ia resolver e tal. Eu tive três reuniões 
lá em Minaçu com eles. Chegava lá diziam que os papéis estavam em São Paulo, nos Estados Unidos, no Japão. E foi tapeando, tapeando, até hoje e aí pra Dr. Arthur pra fazer exame, e ele disse: "Seu marido morreu foi de asbestose. (VIÚVA - OLÍVIA, 2008)

"Tanta coisa que ele sentia. Tinha placa do minério. Disse que tinha [...] Eu nem sei o que têm nesses papéis... que atingiu por dentro do pulmão. Era uma plaquinha, não sei quantos milímetros que tinha". (VIÚVA - BEATRIZ, 2008)

O que se passou nos corpos desses mineiros, foi um conjunto de sinais e sintomas descritos e significados por suas viúvas, que assistiram os corpos de seus maridos se modificarem, mudando suas fisionomias, cor da pele e dimensões corporais. Os relatos se assemelham à literatura médica, ainda que seja numa linguagem simples e afetiva (sobre tema semelhante, mostra Luc Boltanski em sua obra As classes Sociais e o Corpo, 2004). Essa vivência descrita, minimamente, entra em sincronia com a percepção do sentido de indignação pela injustiça sofrida por este trabalhador que "deu a vida à Empresa", no dizer de uma viúva.

Quando ele faleceu, tinha minério nos pés. Saía que nem um cravo. Aquilo brotava assim de dentro pra cima, aquela pontinha arranhava, aí tinha mês que ele cortava, aí ficava ruim do pé. Não tinha mais paladar, a cor dele era amarela, parecendo uma pessoa pálida e ficou magrinho [...]. Trabalhou trinta anos, sem perder um dia de serviço, ele não recebia reclamação, não chegava atrasado nunca. (VIÚVA - JANDIRA, 2008)

A falta de informação médica, fez com que estas pessoas só percebessem o adoecimento e o risco de contaminação quando havia manifestação da doença: "Ele sentia cansaço e falta de ar. Quem sente dessa doença, só sente dor nas pernas e cansaço; ele ia na rua, parava umas dez vezes. Ficava amarelão e uma escuridão que dá no corpo que fica preto, a pele dele estralada". (VIÚVA - OLÍVIA, 2008)

Dispneia, emagrecimento, dores no peito, tosse e cansaço são alguns dos sintomas e sinais da doença. O "mal do minério" é compreendido como o mal da mina. Muitos adoeceram com diagnósticos de tuberculose e pneumonia, como forma de desresponsabilizar a Empresa mineradora por doenças provocadas pelo amianto. Não existia um órgão fiscalizador que pudesse ajudar os trabalhadores, no sentido de 
apontar um tratamento adequado para as doenças do amianto e fazer o contraponto do diagnóstico, muitas vezes negado.

A Empresa mineradora não se comprometeu em cuidar dos ex-trabalhadores doentes e colocava a responsabilidade no governo como um provedor ausente das medicações necessárias. A doença dos maridos para estas mulheres é "um mal que não tem cura". A dedicação do marido ao trabalho é percebida como um esforço que não valeu à pena viver, que não gerou estabilidade financeira, e só produziu adoecimento e morte.

Chama a atenção algumas expressões, como o significado da placa pleural, que para elas é a marca da doença. O primeiro sinal descrito no corpo contaminado.

A placa pleural é tirada do intestino, a placa do minério cozido, placa amarela. Parece que o tumor era da placa entre o couro e a carne. Migue [...] Ficou dessa cor (amarela). Fez o exame de ultrassom. Lá no hospital fez a limpeza na placa, era uma água grossa que nem uma coisa dissolvida, que nem fubá de milho dissolvido no leite. Na barriga estava aquela água grossa, pocou, murchou a barriga. Teve que enterrar logo ele (VIÚVA - ISABEL, 2008). (Esse trabalhador morreu de câncer de estômago conforme a entrevista de sua viúva).

A narrativa seguinte revela que algumas mulheres recorrem ao tratamento alternativo como solução para este mal do minério:

O mal atingindo, aquele pó entrando... o minério. Ele estava sentindo um entupimento no nariz, achava que era do pó do minério e sentia uma gastura na garganta, a garganta cheia de farinha ficava sem poder mastigar. Ele não queria ver cheiro de comida, o nariz dele estava cheio de pau. Eu peguei a paulista que é uma bucha amarga que nem fel [...] tem uma sementinha preta. Bati o pó bem batido e fervi e ele colocou dentro do nariz e respirou esse pó e foi soando o nariz e foi saindo carnegão, amarelo, depois saía azul, saía amarelo da pedra do minério, saía azul [...] que nem a lama. (VIÚVA STELA, 2008)

A desinformação quanto às doenças dos maridos, a falta de assistência da Empresa mineradora e dos agentes de saúde do Estado em relação às viúvas e suas famílias, são ainda visíveis em Bom Jesus da Serra. A Empresa manipulou informações e se apresentou em visitas às casas das viúvas, reivindicando documentos e exames realizados por 
seus maridos, com o discurso de rever direitos trabalhistas a serem repassados às viúvas, mas ainda não houve qualquer solução.

As famílias que reivindicam direitos sociais (benefícios previdenciários) sofrem com a indiferença do serviço social da Empresa mineradora: "A firma não ajuda mais no funeral dos que morrem, porque teve reunião na (ABEA) e eu fui e diz que eu não deveria ter ido, que ficou ruim e que os chefes lá da empresa cortaram o benefício por isso". (VIÚVA - BEATRIZ, 2008)

As providências que podem ser tomadas pelas viúvas e familiares para reaver seus direitos, são ainda incipientes. A busca por indenizações passou a ser o motivo central da Associação dos trabalhadores. Mas, como não há atestados de óbitos registrados com o nexo causal relacionado à morte à exposição ao amianto, observa-se um sentimento de desesperança. Também, a devassa realizada pela Empresa nas casas das viúvas e de seus familiares, na busca de documentos que pudessem comprometer a Empresa (exames de saúde), logo após as primeiras mortes, resultou numa condição social de solidão, humilhação e desespero por parte das viúvas. Sentem-se invadidas, sem apoio de autoridades públicas, e sua Associação é a única alternativa que encontram para reunir os interesses da comunidade e procurar soluções.

Eu nem pensei em mais nada da empresa, porque está sendo muito difícil pra gente. Sairpra procurar, pra mexer com isso, eu não quero me envolver mais. Agora, se for uma coisa pra continuar, ir paras reuniões eu posso acompanhar. Mas pra correr atrás, eu não corro, porque pra mim o mais importante já foi: a vida dele. (LIA, FILHA DA VIÚVA BEATRIZ, 2008)

O movimento social da ABEA funciona como único movimento contrário à Empresa na busca das indenizações das vítimas. Tem encontrado, ao longo do tempo, embates com o poder judiciário. ${ }^{1}$ A ABREA, em Bom Jesus da Serra, vem buscando soluções judiciais para ex-trabalhadores (indenizações trabalhistas), e informa aos moradores de toda a região sobre os perigos inerentes no lidar com o amianto no seu estado natural, e com subprodutos industrializados, fazendo

1 Existe uma ação judicial movida pela ABEA contra a empresa desde 2001. Em 2008, através da Ação Civil Pública e como resultado de um termo de ajuste de conduta firmado pelo Ministério Público do Trabalho com a Secretaria de Saúde do Estado da Bahia e secretarias municipais da região, alguns mineiros e seus parentes passaram a serem avaliados clinicamente, com o objetivo de medir os impactos da saúde e definir tratamentos. 
dessa uma ação política que busca banir o amianto definitivamente do Brasil (como acontece em vários países).

Apesar dos maridos terem dedicado parte de suas vidas à Empresa mineradora, não houve qualquer tipo de direito trabalhista assegurado aos ex-trabalhadores e suas famílias. O salário que recebiam pelo trabalho era direcionado apenas à subsistência das famílias. Depois que a mina foi desativada e os maridos morreram, essas mulheres nunca foram procuradas pela Empresa mineradora para discutir os seus direitos. Elas se sentem abandonadas:

A ajuda mesmo pra meu marido foi só dos nossos filhos. Uma casinha que ele tinha lá no sul não tem nada a ver com o dinheiro da empresa. Quando ele vendeu esta casa ele comprou uma criaçãozinha, mas tudo foi acabando. O resto quem deu foram os filhos, os netos . (VIÚVA - BEATRIZ, 2008).

Durante o adoecimento e morte, a família tem sido o principal apoio, inclusive financeiro. A Empresa mineradora fornece plano de saúde aos trabalhadores mais doentes e quando estes morrem não recebem qualquer tipo de ajuda. $\mathrm{O}$ fato de não receberem indenizações, é compreendido pelas viúvas como "usura e egoísmo" dos que detém o poder. A omissão dos agentes do Estado e o descaso dos empresários da mineradora são evidenciados nos relatos dessas mulheres.

"A Empresa veio aqui depois. A gente tinha os exames todos que ele (o marido) fez. Eles (responsáveis pela empresa) sumiram com todos os exames e documentos". (VIÚVA OLÍVIA, 2008)

"Quando eu fui pedir ajuda à Empresa, eles queriam só pagar a minha passagem de ônibus. Isso é egoísmo, usura”. (VIÚVA D. BEATRIZ, 2008).

A partir de 2010, o Centro de Estudos da Saúde do Trabalhador (CESAT), instituição da Secretaria Estadual de Saúde da Bahia, em parceria com o Centro de Referência em Saúde do Trabalhador (CEREST) da Secretaria de Saúde de Vitória da Conquista, vem realizando o cadastramento dos ex-trabalhadores para a realização de exames no SUS, no município vizinho, Vitória da Conquista. 


\section{O cotidiano da morte: o ritual do sepultamento}

A morte é um momento a ser partilhado com a família, entre parentes e vizinhos. A percepção mítica que envolve interpretações sobre a morte, marca a presença contínua do morto no imaginário dos parentes. Depois do sepultamento, cumpre-se um ritual de purificação em relação à separação do morto e do cemitério, principalmente do contato com a "terra contaminada", se dá com a realização de alguns critérios: não entrar em casa com os sapatos utilizados no funeral; tomar banho completo, incluindo lavar os cabelos; lavar todas as roupas e os calçados que tiveram algum contato com o "morto", podendo contaminar a casa com as impurezas do morto. Nesse sentido, a purificação é necessária para retornar ao estado anterior, desvinculado os vivos da morte. É possível perceber que, para além de servir de proteção contra possíveis doenças, a purificação tem um sentido de novamente colocar vida e morte em oposição. (DOUGLAS, 1976)

Inserem-se, neste contexto, narrativas que ilustram percepções sobre a viuvez como se fosse parte da vida perder seus companheiros precocemente. A morte desses trabalhadores da mina de São Félix, marca a vida de todas as famílias que ali vivem. Morreram pela contaminação e por condições violentas de trabalho:

\footnotetext{
Morreu tanta gente nessa mina! Morreu muita gente, de tomar pancada, de bater pedra. Tinha um vagão que quando descia, o pessoal tinha que se esconder num cantinho, porque o vagão batia e esmagava quem ficasse perto. E morreu muita gente lá embaixo, esmagada. A pedra do corte que dava fogo estourava NAS EXPLOSÕES. Morreu foi gente. Era pedra pra estourar, pra poder botar pra fazer minério, porque tinha dinamite que explodia. (VIÚVA - JOSEFA, 2008)
}

Manoel Cândido era o feitor geral da mina, conhecido por todos que lá viveram. Era ele quem comandava os operários. Ele e outros seguiram trabalhando na Empresa, em Minaçu, Goiás e morreram por lá. Entre as causas das mortes destaca-se: tuberculose, pneumonia, derrame pleural, câncer e Acidente Vascular Cerebral. Qualquer morte é compreendida como condenação por ter trabalhado e ter tido contato com o amianto: "Morreu Manoel Cândido, morreu o irmão, morreu genro, morreu tudo em Goiás. Disse que morreu porque todo mundo 
que trabalhou nessa mina, morreu. Não tem nenhum vivo". (VIÚVA D. JOSEFA)

Os ex-trabalhadores da mina que foram expostos à poeira do amianto, estão doentes ou morreram. Isso reflete a tendência mundial de morte de mineiros, que não tiveram acesso à proteção individual e coletiva nos postos de trabalho, na atividade de mineração. (SCAVONE, 1997) Os únicos exames feitos pelos trabalhadores são os realizados pela Empresa mineradora, que entrega laudos sem registros de doenças, dando a impressão que nenhum deles está doente ou morreu por causa da exposição ao amianto. Como podemos observar nesta narrativa:

Tem o compadre Zé, cunhado de Margarida, que está doente. Tem meu cunhado também, ele foi prejudicado do minério, disse que tem a manchinha no pulmão. Todos que têm o plano de saúde têm algum problema do minério. A empresa só dá plano pra quem atingiu do minério. Os resultados dos exames que fala que foi a plaquinha, essa coisa toda aí. Tem meu irmão lá em Poções. Trabalhou, trabalhou foi muito. Compadre Zé aqui trabalhou também em Minaçu, o cunhado de Lia. Morreu outro que chamava Nivaldo. Morreu todos declarados do minério, todos morreram. Morreu o que teve problema de pulmão também, Aílton. Tem Antenor lá de Poções. Néu até disse também: - "Antenor morreu foi também desse minério". Aí o médico da empresa disse: - "Não, é porque esse aí teve foi enfarte". Mas foi do minério também. Ninguém conta os que morreram". (VIÚVA - BEATRIZ, 2008)

A morte tem o ritual de despedida afetivo. Participar de todo o ritual, como: vestir o morto e velar por toda a noite, não parece ser um evento comum como em outros velórios. Neste, predominava o sentido de morte por amianto, morte pelo trabalho da mina. A descrição reflete o medo que se tinha de contaminar-se e de ser o próximo a morrer. Depois do enterro, vem o cuidado e a dedicação aos túmulos. A ida aos cemitérios faz parte do cotidiano das viúvas que revelam resignação, conformidade aos desígnios divinos, não cabendo mais denunciar o descaso histórico da Empresa mineradora e do Estado por estas terem se ausentado do tratamento da doença dos trabalhadores. Para as viúvas e seus familiares, resta a indenização, que ainda requerem. Relembrar as consequências da contaminação, doença e morte de seus maridos, ex-trabalhadores da mina, é um conflito que elas não querem mais reviver. Entre a denúncia de morte por contaminação e o conformismo pela perda de seus maridos, há um silêncio de dor e falta. 
Não há uma contradição aparente nestes processos, mas um conflito entre a explicação a interpretação, desde a contaminação à morte.

\section{Considerações finais}

Existe um passado de lembranças e tragédias, mas a convivência com a pedra de amianto é naturalizada em Bom Jesus da Serra. Isso faz parecer que lidar com este objeto não faz qualquer mal aparente. É como se coubesse a pergunta: "afinal de contas, que mal tem em bater umas pedrinhas, uma nas outras e retirar as lãzinhas?" O que foi uma consequência maléfica no passado, permeia ludicamente o universo cotidiano e o simbólico até os dias de hoje e adquire forma naturalizada pela comunidade, como se não houvesse perigo implícito ao lidar com este minério, "a pedra". O conhecimento e a experiência do cotidiano, a relevância da necessidade de trabalhar para o sustento da vida, trata com naturalidade, interagem entre si e exercem influência sobre o homem.

O estrago causado ao corpo e à comunidade, por este minério, resulta do abandono da Empresa e dos agentes do Estado aos familiares enlutados. O movimento social dos trabalhadores resgata esta discussão, para tomar providências em relação às vítimas, culpados e omissos desta situação.

Como resultado desse abandono, as viúvas convivem com a Empresa que ainda exerce poder sobre elas, devido à falta de apoio do Estado e de informações sobre seus direitos e soluções. As famílias que buscaram seus direitos não conseguiram seguir com suas ações contra a Empresa. Não apareceram ainda advogados que queiram conduzir os casos e que lutem por elas. Os moradores de Bom Jesus da Serra se sentem "esquecidos", como se estivessem num lugar sem proteção legal e sem amparo institucional do Estado.

A resistência das viúvas, apesar da sua aparente submissão, é revelada na história e no cotidiano de cada uma, de como compreendem e conseguem se expressar sobre a contaminação e a morte de seus companheiros. O "calar" e a aparente aceitação implícita das relações de poder, por parte de alguns ex-trabalhadores e viúvas, tem sustentação nas precárias condições de sobrevivência. 
O processo de discussão sobre a situação do amianto, em Bom Jesus da Serra é bem mais complexo do que no resto do país. Tendo sido a primeira mina explorada no Brasil, mantém a relação do homem com o amianto in natura. E, por isso, requer uma política de educação em saúde ambiental direcionada ao local.

Nascer, viver e morar no entorno da mina, tem um significado profundo para estas pessoas. A proposta de interdição da mina significa não ir mais nadar, pescar, passear, lavar roupa, coisas que ainda fazem parte do cotidiano desses moradores.

Nesse sentido, ações de comunicação e educação em saúde precisam ser mais elaboradas para que haja um sentido de competência comunicativa, com informações repassadas e compartilhadas entres os membros da comunidade. (RANGEL, 2008) Para o caso aqui estudado, a vocalização de demandas quanto à contaminação ambiental por amianto no município, não só das viúvas e de seus familiares, mas da comunidade de Bom Jesus da Serra, pode ser vista como um começo para a construção compartilhada de soluções para essa complexa questão ambiental. A população local ainda não foi esclarecida, nem consultada, e a comunicação é aqui assumida enquanto recurso para redução da iniquidade social que acentua a vulnerabilidade desta comunidade à contaminação ambiental. Ao tomar a vulnerabilidade, como proposto por Meyer e colaboradores (2006), a comunicação é aqui defendida, enquanto dimensão do cuidado à saúde e requer tomar a contaminação ambiental por amianto em Bom Jesus da Serra, a partir da visibilidade do fenômeno construída pela comunidade e seus modos de apropriação e atribuição de sentidos. Nesse aspecto, é importante examinar as condições contextuais de trocas simbólicas entre os pares (comunidade e movimento social) e sua competência comunicativa na inserção política com atores sociais, com diferentes interesses nesta questão.

É de se esperar que a proposição de uma efetiva política de saúde ambiental, direcionada a esta realidade, possa mudar definitivamente a realidade de resignação e conformidade das famílias dos trabalhadores mortos pelo amianto, fruto do poder da Empresa e ausência de justiça social. 


\section{Referências}

ABREA - Associação Brasileira de Expostos ao Amianto. História do Amianto. 2001. Disponível em:

<http://www.abrea.org.br>. Acesso em: 22 abr. 2007.

ADFA - Asbestos Disease Foundation of Australian.

History. Disponível em < http://www.asbestosdisease.au/

historyasbestos.aspx > Acesso em: 11 jan. 2009.

AFL-CIO da Oil, Chemical and Atomic Workers International Union, 1995.

ALVES. P. C. A Experiência da Enfermidade. Cadernos de Saúde

Pública, Rio de Janeiro, v. 9, n. 1, p. 263-271. jul. - set. , 1993.

. A fenomenologia e as Abordagens Sistêmicas nos Estudos Sócio-Antropológicos da Doença: breve revisão crítica. Cadernos de Saúde Pública, Rio de Janeiro, v. 22, n. 8, p. 1547-1554, ago. 2006.

; RABELO, M. (Orgs. ). Antropologia da Saúde: traçando identidade e explorando fronteiras. In: Alves, P. C; Rabelo, M. Repensando os Estudos sobre Representações e Práticas em Saúde/Doença. Rio de Janeiro: Relume Dumará/Fiocruz, 1998. p. 107-121. ; MINAYO, C. (Orgs. ) Saúde e Doença: um olhar antropológico. Rio de Janeiro: Fiocruz, 1994. p. 153-66.

ASBESTOS - News PaperArhive - History - Disponível em <http:// www.asbestosarchive.com/history.aspx > Acesso em: 15 jan. 2009.

BAHIA. ASSEMBLÉIA LEGISLATIVA DA BAHIA. Comissão de Proteção ao Meio Ambiente. Amianto, Desinformação

Mata. Bahia: Grifo/Audiovisual, 2004.

BARBIERI, J. C. Desenvolvimento e Meio Ambiente: as estratégias de mudanças da Agenda 21. Petrópolis: Vozes, 1997.

BARTHES, R. A. Aventura Semiológica. São Paulo: Martins Fontes, 2001.

BEAUVOIR, S. A. Velhice. Rio de Janeiro: Nova Fronteira, 1990.

BECK, H. Sociedade de Risco: rumo a uma outra modernidade. São Paulo: Ed 34, 2010.

BECKER H. S. Métodos de Pesquisa em Ciências

Sociais. São Paulo: Hucitec; 1994.

BENJAMIM, W. O Narrador. In. : TEXTOS ESCOLHIDOS.

São Paulo, Abril Cultural, 1980. Col. Os pensadores. 
BENJAMIM, W. Obras escolhidas: magia e técnica, arte e política, 3 ed. São Paulo: Brasiliense, 1987.

BERGER, P; LUCKMAN, T. A Construção Social da Realidade: tratado de Sociologia do Conhecimento. Petrópolis: Vozes, 2004.

BOLTANSKI, L. As classes sociais e o corpo. Trad. Regina Machado. Rio de Janeiro, 4. ed. São Paulo: Graal, 2004.

BOSI, E. Memória \& sociedade: lembrança de velhos. São Paulo: T. A. Editor, 1979.

BRAITH, B. Bakhtin e Outros Conceitos - Chaves. São Paulo: Contexto, 2006.

BRASIL, Ministério da Saúde do Brasil. Representação no Brasil da OPAS/OMS. Doenças Relacionadas ao Trabalho - Manual de Procedimentos para os Serviços de Saúde. Série A Normas e Manuais Técnicos, Brasília, n. 114, 2008. p. 291.

BROSIUS, J. P. Analyses and interventions. Anthropological engagements with environmentalism. Current Anthropology, v. 40, n. 3, p. 277-309, 1999.

CASTLEMAN, B. Building a future without asbestos. New Solutions - Journal of Environmental and Occupational Health Policy, Lakewood, v. 5, n. 2, p. 58-63. 1995.

. Asbestos: Medical and legal aspects. 4 ed.

New york: Aspen Law \& Business, 1996.

. Responsible Care and the Third World. Environmental Health Perspectives, v. 1, n. 105, p. 16-17, jan. 1997.

CASTRO, H.; GIANNASI, F; NOVELO, C. A Luta pelo Banimento do Amianto na Américas: uma questão de Saúde Pública.

Cadernos de Saúde Pública, v. 4, n. 8, p. 903-911, 2001.

D'AREDE, C. O Tempo das Águas e dos Ventos: significações do asbestos atribuídas às viúvas e ex-trabalhadores da Mina de São Félix, em Bom Jesus da Serra, Bahia. 2009. Dissertação (Mestrado em Saúde, Ambiente e Trabalho) Faculdade de Medicina da Bahia, Universidade Federal da Bahia, Salvador, 2009.

DICKINSON, E. Poemas Escolhidos. Porto Alegre: L\&PM, 2008

DIEGUES, A. O Mito Moderno da Natureza Intocada.

São Paulo: Hucitec, 2004. 
DOUGLAS, M. Pureza e Perigo. Ensaio sobre as Noções de Poluição e Tabu. Lisboa: Edições 70, 1991. (col. Perspectivas do Homem, n. 39).

DURAND, G. A Imaginação Simbólica. São Paulo: Cultrix, 1993.

FERREIRA, A. M. C. A linguagem Originária. Salvador: Quarteto, 2007

FOLADORI, G.; TAKS, J. Um Olhar Antropológico sobre a questão Ambiental. Mana, v. 10, n. 2, p. 323-348, 2004.

FRIEDSON, E. Profession of Medicine. Chicago:

The University of Chicago Press, 1988.

GEERTZ, C. A Interpretação das Culturas. In: GEERTZ, C. Uma Descrição Densa: por uma teoria interpretativa da Cultura. Rio de Janeiro: Editora Guanabara, 1999.

. O Saber Local: novos ensaios em antropologia interpretativa. In: Do ponto de vista dos nativos. Petrópolis, RJ: Vozes, 1997.

. Nova luz sobre a Antropologia. Rio de Janeiro: Jorge Zahar, 2001.

GIANNASI F.; MONY, A. T. Occupational Exposures to Asbestos in Brasil. International Journal of Occupational Environmental Health (IJOEH), 3, Hanley \& Belfus, INC. , Philadelphia, EstadosUnidos, 1997, p. 150-157.

GIANNASI, F. Asbesto / Amianto no Brasil. Um Grande Desafio. Caderno CRH-Centro de Recursos Humanos da Bahia da Universidade Federal da Bahia (UFBA), n. 23, p. 128-140. Jul. /dez. 1995.

GONÇALVES, M. A.; MARQUES, R; CARDOSO, V. Etnobiografia: esboço de um conceito. In. : . (orgs), Etnobiografia: subjetivação e etnografia. Rio de Janeiro: Edt. 7 Letras, 2012. p. 9-42.

GOOD. B. Medicine, rationality, and experience: an anthropological perspective. Cambridge: Cambridge University Press, 1994. . The Heart of What's the Matter: The Semantics of Illness in Iran. Culture, Medicine, and Psychiatry, n. 1, p. 25-58, 1976.

; GOOD, M. J. The Meaning of Symptoms: a Cultural Hermeneutic Model for Clinical Practice. In: L. Einserberg\& A. Kleinman. The relevance of social science for medicine. Boston: D. Reidel Publishing Company, 1980.

HALL, S. A Centralidade da Cultura: notas sobre as revoluções culturais do nosso tempo. Educação e Realidade, v. 22, n. 2, p. 15-46, 1997. HELMAN. Cultura Saúde e Doença. In: Tratamento e Cura: as alternativas de assistência à saúde. Porto Alegre: Artes Médicas, 1994. 
HUSSERL, E. A. Crise da Humanidade Europeia e a Fenomenologia. Trad. Urbano Zilles. Porto Alegre: Edipucrs, 1996.

IBAS - International Ban Asbestos Secretariat, s. d. Disponível em: < http://ibasecretariat. org/> Acesso em: 12 jan. 2009.

KLEINMAN, A. et al. Pain as human experience.

Berkeley: University of California Press; 1994.

. Patients ND Healers in the Context of Culture: an exploration of the Borderland between Anthropology, Medicine, and Psychiatry. California: University of California press: Berkeley Los Angeles, 1994.

. The Illness Narratives: Suffering, Healing and the Human Condition. New York: Basic Books, 1988.

KUPER, A. Anthropologists and Anthropology: The British school (1922-1972). New York: Pica Press, 1973.

LEFF, E. Saber Ambiental. Petrópolis: Vozes, 2001. 343 p.

LÉVI-STRAUS C. O Pensamento Selvagem. Campinas, SP: Papirus, 1989.

LOPATA, H. Current Widowhood: myths and realities.

Thousand Oaks, CA: Sage Publications, 1996.

LOYOLA, M. A. Médicos e Curandeiros Conflito Social e Saúde. In: As

Doenças, os Doentes e os Especialistas. São Paulo: Ed. Difel, 1984.

LECLERC, G. Antropología y Colonialismo. Madrid:

Ed. Comunicación, 1973.

MENDES, R. Asbesto (amianto) e Doença: Revisão do

Conhecimento Científico e fundamentação para uma urgente

mudança da atual política brasileira sobre a questão. Cadernos

de Saúde Pública, Rio de Janeiro, v. 17, n. 1, p. 07-29, 2001.

MEILLASSOUX, C. Mulheres, Celeiros e Capitais.

Lisboa: Afrontamento, 1977.

MEYER, D. E. E. et al. “Você aprende. A gente ensina?”Interrogando relações entre educação e saúde desde a perspectiva da vulnerabilidade. Cadernos de Saúde Pública, Rio de Janeiro, v. 22, n. 6, p. 1335-1342, jun. 2006.

MINAYO, M. C. O Desafio do Conhecimento: pesquisa qualitativa em saúde. São Paulo: Hucitec Abrasco, 1992.

MONTAIGNE, M. Ensaios. . Rio Grande do Sul: Globo, 1961. v. 51, Coleção Biblioteca dos Séculos. 
MORIN, E. La méthode 4. Les ideés, leur habitat, leur vie, leurs moeurs, leur organization. Paris: Seuil, 1991.

MOTTA, A. B. Viúvas, O Mistério da Ausência. Estudos Interdisciplinares de Envelhecimento. Porto Alegre, 2005.

OLIVEIRA, R. C. de. O trabalho do Antropólogo.

2 ed. São Paulo: Editora UNESP, 2000.

PAMPLONA, R. O Amianto Crisotila e a SAMA: 40 anos de História Minaçu-Goiás. 1962-2003. Minaçu-GO, 2003.

PARSONS, T. The Social System. London: Routledge \& Kegan Paul, 1951.

RABELO, M.; ALVES, P. C.; SOUZA, I. A Experiência de Doença e Narrativa. Rio de Janeiro: Fiocruz, 1999.

PIZZI, J. O mundo da vida: Husserl e Habermas. Ijuí: Editora Unijuí, 2006.

PORTO, M. F. de S. Uma Ecologia Política de Riscos: princípios para integrarmos o local e local na promoção da saúde e da justiça ambiental. In: Riscos, Saúde e Vulnerabilidade: em Busca de uma Ciência Sensível. Rio de Janeiro: Fiocruz, 2007.

RAMOS, G. Vidas Secas. Rio de Janeiro: Record, 2008.

RICOEUR, P. Teoria da Interpretação. Lisboa: Ed. 70, 2009.

. Tempo e Narrativa. Campinas, SP: Papirus, 1994. 1v.

RANGEL, M. L. Cultura, Tecnologias em Saúde e Medicina. In: CAROSO, C.

Notas para uma Etnografia da Comunicação em Serviços de Saúde.

(Org. ). Perspectiva antropológica. Salvador: EDUFBA, 2008.

SCAVONE, L. Invisibilidad social de dolenciasprofesionales ligadas

a laexposicion al amianto. In Cuadernos Mujer Salud/2. Trabajo

Y Salud. Mujeresen Riesgo. Publica oda Red de Salud Delas

Mujeres Latino americanas Y Caribe. n. 2, 1997, p. 143-147.

; GIANNASI, F; TÉBAUD-MONY, A. Cidadania e Doenças

Profissionais: o Caso do Amianto. São Paulo: ABRA, 1996.

Amianto e suas consequências sóciofamiliares:

uma abordagem comparativa franco-brasileira. Relatório

Final de Pesquisa, INSERM/CNPq, 1997.

SARTRE, J. P. Esboço de uma Teoria das Emoções.

Lisboa: Editorial Presença, 1972. 
SCHUTZ, A. Schutz A. O mundo da vida. In: WAGNER, H. R. Fenomenologia e as relações sociais (Org.).

Rio de Janeiro: Zahar Editores, 1979.

SCOONES, I. New Ecology and the Social Sciences: What Prospects for a fruitful Engagement? Annual Reviewof Anthropology, v. 28, p. 479- 507, 1999.

SILVA, D. TRENTINI, M. Narrativas como Técnica de Pesquisa em enfermagem. Revista Latino Americana de Enfermagem. 2002. v. 10, n. 3, p. 423-432, maio-jun. 2002.

SOUZA, E. C. A arte de contar e trocar experiências: reflexões teóricometodológicas sobre história de vida em formação. Revista Educação em Questão. Natal, Ed. UFRN, v. 25, n. 11, p. 22-39, jan. /abr. 2006.

THOMPSON, P. B.; DEAN, W. E. Competing Conceptions of Risk. New Hampshire: Franklin. Pierce Law Center, 1996.

TIEZZI, E. Tempos Históricos, Tempos Biológicos - A Terra ou a Morte: Os Problemas da Nova Ecologia. São Paulo: Nobel, 1988.

UNIVERSIDADE ESTADUAL PAULISTA - UNESP - Silicatos Crisotila Disponível em: <http. www.rc.unesp/museudpm/banco/ silicatos/filossilicatos/crosotila.html> Acesso em: 12 de jun. 2008. 